\title{
Artelogie
}

Recherche sur les arts, le patrimoine et la littérature de l'Amérique latine

2 | 2012

Mexique : espace urbain et résistances artistiques et littéraires face à la « ville générique »

\section{La escultura monumental en acero inoxidable, una tradición en Tultepec}

\section{Susana Villafuerte}

\author{
(2) OpenEdition \\ Journals \\ Edición electrónica \\ URL: https://journals.openedition.org/artelogie/7937 \\ DOI: $10.4000 /$ artelogie. 7937 \\ ISSN: 2115-6395 \\ Editor \\ Association ESCAL
}

Referencia electrónica

Susana Villafuerte, «La escultura monumental en acero inoxidable, una tradición en Tultepec», Artelogie [En línea], 2 | 2012, Publicado el 21 enero 2012, consultado el 07 enero 2022. URL: http:// journals.openedition.org/artelogie/7937 ; DOI: https://doi.org/10.4000/artelogie.7937

Este documento fue generado automáticamente el 7 enero 2022.

Association ESCAL 


\title{
La escultura monumental en acero inoxidable, una tradición en Tultepec
}

\author{
Susana Villafuerte
}

1 Este artículo trata del movimiento de escultura monumental en acero inoxidable que promueve Miguel Hernández Urbán en Tultepec, municipio agrícola del Estado de México. Hernández Urbán ha propuesto utilizar un material moderno para expresar la mexicanidad e incita a los escultores de todo el mundo a compartir en la práctica creativa un diálogo de culturas y de símbolos. En 1992 organizó el primer "Simposio de Escultura en Acero Inoxidable" en su comunidad natal, cuna de destacados músicos, pintores y escultores.

2 Cada año, desde hace casi veinte, el trabajo de realización de esculturas se une durante algunas semanas a las actividades de preparación de la Feria de Juegos Pirotécnicos: la elaboración de decorados de flores naturales para la iglesia, la fabricación de las enormes torres pirotécnicas, la creación de los "toritos" que desfilan antes de ser quemados... Todo ello en una intensa convivencia entre toda una población creativa, con paseos entre árboles de pirul, eucaliptos, algo de pulque, tequila y comida regional. La importancia en el país del resultado de este simposio es indudable, las obras resultantes se exponen en el Paseo de la Reforma de la Ciudad de México, en museos, parques, universidades del país y del extranjero, y algunas de ellas se han incorporado definitivamente al paisaje urbano.

3 ¿Qué tipo de obra escultórica se realiza en ese ambiente cargado de reminiscencias del pasado? ¿Qué marcas quedan en la obra y en el artista tras su paso por Tultepec? ¿Qué impacto tiene en la población local, que convive con el trabajo de los escultores de arte contemporáneos, trabajar el moderno acero inoxidable? ¿Cuáles reinterpretaciones se manifiestan? ¿Qué proyección tiene hacia el exterior? Estas son las primeras preguntas que guiaron este trabajo.

4 Iniciamos con la exposición de las características de este territorio, sus estrategias de recreación y de renovación de expresiones propias que refuerzan su identidad frente a 
la cercanía y avance de la mancha urbana de la zona metropolitana de la Ciudad de México. Abordaremos el caso particular del movimiento de escultura en acero inoxidable, exponiendo finalmente algunas reflexiones acerca del análisis de la producción del arte en el México actual.

\section{Tultepec, territorio de creación}

Imagen 1. Escudo de Tultepec. Glifo de Tultepec. Códice Mendocino

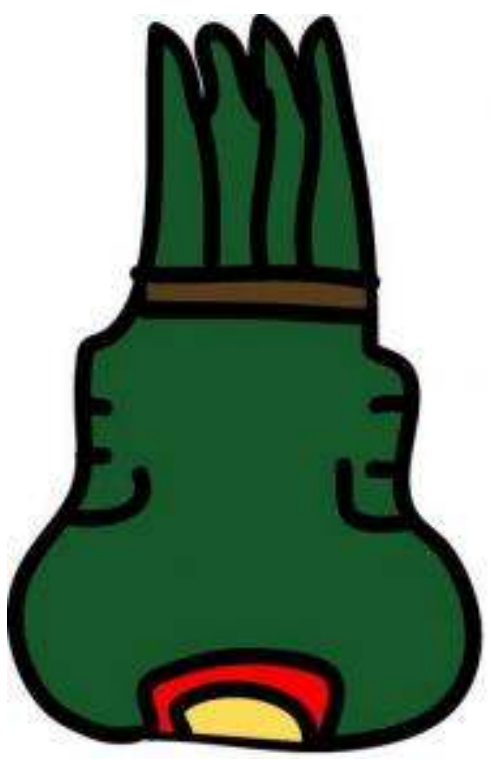

Tultepec - palabra náhuatl que significa "En el cerro del tule"1 - es el nombre que conserva el municipio situado al norte de la zona metropolitana de la Ciudad de México. Compuesto por sembradíos y localidades clasificadas como rurales y agrícolas, alberga a alrededor de cien mil habitantes ${ }^{2}$. Su configuración patentemente rural se mantiene hasta la década de 1980, cuando se inicia una evidente modificación de una parte del paisaje natural y social debido a la construcción de unidades habitacionales y de fraccionamientos. Sin embargo, todavía en 2010 el uso del suelo agrícola se elevaba hasta un $56.84 \%$, pecuario $2.7 \%, 31 \%$ urbano, $2 \%$ industrial y $7 \%$ otros. En las estadísticas oficiales este municipio es catalogado con una industria y servicios incipientes, donde la principal ocupación es en el sector manufacturero, principalmente en el de la pirotecnia, actividad que data de mitad del siglo XIX y que ha consolidado la economía monetaria local. La actividad agropecuaria y ganadera se destina al consumo local.

6 La población de Tultepec mantiene una actividad creativa constante, dinámica y bien estructurada, en permanente renovación. Todos los sectores, agricultores, ganaderos, obreros, estudiantes, cocineras, amas de casa, maestros, artesanos y artistas, participan, adaptan e integran a su forma de ver la vida, materiales nuevos o tradicionales, técnicas antiguas e innovadoras de producción artesanal y artística, utilizan cualquier medio a su alcance para recrear festivamente su identidad comunitaria.

7 La existencia de cerca de sesenta mayordomías habla del predominio de una forma de organización comunal ancestral que permite conservar vigentes las fiestas patronales. El centro de las celebraciones es frecuentemente el Santuario de Nuestra Señora de 
Loreto, construcción del siglo XVI, ubicado en la plaza principal de la población más importante del municipio que lleva el mismo nombre. Para estas fiestas, las familias, los grupos de amigos y los niños elaboran objetos de papel, madera $u$ otros materiales que portan en los "paseos" por las calles de los distintos barrios. De igual manera un buen número de participantes fabrican grandes decorados: los "arcos florales" de vegetación fresca para colocar en la fachada del Santuario. En las entradas colocan tapetes de aserrín, a la usanza prehispánica o colonial, que aunados a las torres pirotécnicas de alrededor de diez metros de alto, muestran el gusto y la costumbre por realizar obras monumentales efímeras.

8 Otras manifestaciones artísticas tienen lugar paralelamente a las fiestas tradicionales. En ellas se han dado a conocer artistas célebres en México en los géneros musical, literario, pictórico, dancístico y escultórico ${ }^{3}$. Dichos artistas también participan en las fiestas, como los músicos que tienen a Santa Cecilia como su patrona. Estas manifestaciones dan origen a distintas organizaciones e instituciones artísticas como la Escuela de Bellas Artes en la que se imparten distintos talleres artísticos. Las exigencias administrativas de la modernización institucional del país y su cercanía a la capital se resuelven de una manera original. Si antes la educación musical tenía lugar en el seno familiar, ahora se imparte en la Escuela de Bellas Artes en un ambiente similar al familiar.

El gremio pirotécnico de Tultepec, importante en el país por sus innovaciones técnicas ${ }^{4}$, también constituye una agrupación religiosa denominada "Asociación de San Juan de Dios" que celebra su propia fiesta cada 8 de marzo. Esta fecha sirve para realizar la Fiesta Nacional de la Pirotecnia, principal actividad del gremio. Es de notar que en el calendario de festividades de Tultepec las fiestas patronales frecuentemente coinciden con otras manifestaciones que son consideradas parte de la tradición local, como el “Festival de Órgano" y el "Simposio Internacional de Escultura en Acero Inoxidable".

Imagen 2. "Foto de familia". Escultores y población de Tultepec en el Taller del Simposio

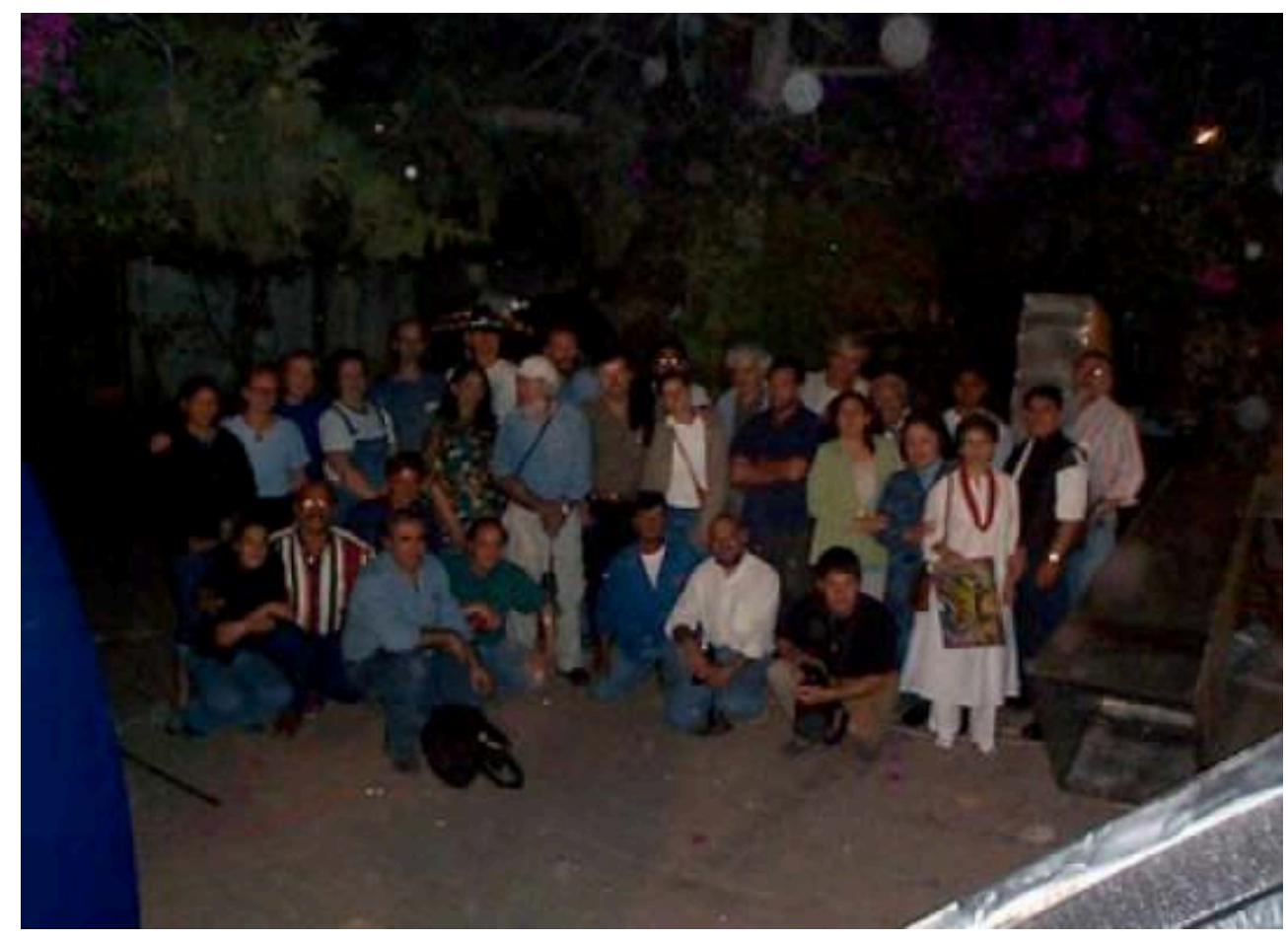


10 Pensar un territorio considerado agrícola como fuente de creación artística contemporánea que utiliza un material moderno, puede parecer extraño si sólo se compara los conceptos de arte y artesanía, población urbana y población rural, tradición y modernidad. Para comprender cómo un movimiento de escultura monumental en acero inoxidable se relaciona con la práctica creativa de la población, propongo reflexionar este caso particular pensando la actividad de creación como un proceso compartido, como una práctica estética creadora de un patrimonio artístico de los tutelpequenses (Sennet 2010, Heinich 2010). La experiencia estética en Tultepec es al mismo tiempo un trabajo individual y un trabajo colectivo de expresión y de colaboración, ya que los escultores comparten el proceso de realización de una obra con la comunidad. Finalmente, la obra terminada se suma al patrimonio de la comunidad.

\section{El arte como experiencia}

\section{(Recordando el título de una obra de John Dewey)}

11 El principal impulsor del movimiento de escultura monumental en acero inoxidable es Miguel Hernández Urbán (1936, Tultepec). Pintor y escultor, participante activo desde niño en actividades musicales y de elaboración plástica en el ambiente familiar y comunal, inició formalmente sus estudios artísticos en la Escuela Nacional de Artes Plásticas. Más tarde, continuó en la Academia de San Carlos de la Universidad Nacional Autónoma de México, vinculándose a la Escuela Mexicana de Pintura. Su trabajo está influenciado por Ignacio Asúnsolo, Luis Ortiz Monasterio y Antonio Rodríguez Luna, quienes fueron sus maestros, así como por su participación como ayudante de David Alfaro Siqueiros y José Chávez Morado. Obtuvo una beca del gobierno francés lo que le permitió abrirse a otras influencias. Tras volver a su tierra natal se reintegró a la dinámica cultural.

12 Hace más de veinte años Hernández Urbán empezó a explorar la utilización del acero inoxidable en su trabajo como escultor ${ }^{5}$. En ese material encontró un símbolo del progreso tecnológico y de la modernidad urbana, pues es utilizado principalmente en la construcción de grandes edificios y en los aparatos electrodomésticos. Hernández Urbán quiere usarlo para expresar su mexicanidad. Para él, el acero inoxidable es un material "propio de la región" debido a que puede obtenerse en la zona, debido a la industria metalúrgica instalada en los municipios circundantes a Tultepec. Aprecia las cualidades de este material: "refracta la luz solar haciéndola un objeto vivo que en el día forma diferentes matices y formas". Además es un metal ligero, fácil de trasladar, resistente y maleable que se puede trabajar para hacer esculturas en gran formato y se conserva bien en el exterior.

13 No son extrañas las referencias a la importancia de la luz solar y a las características que percibe de él. Puede ser una evocación al pasado, donde el sol es un elemento central de la visión del mundo precolombino: fundamental para la medición del tiempo - calendario solar mexica, por ejemplo-, en la construcción de ciudades y edificios - Teotihuacán es un ejemplo ampliamente conocido - e indispensable en los rituales. Estas ideas quizás se unen con el concepto de la escultura actual como una organización de la materia en forma tridimensional, una intervención en el espacio que incluye la dimensión espacio-tiempo. 

un llamado a otros artistas, artesanos y personas interesadas, para compartir este diálogo con la materia. Propuso hacerlo retomando el antiguo significado griego de

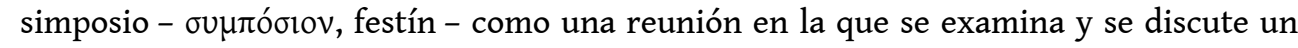
tema de manera amistosa ${ }^{6}$. Hernández Urbán se propone fomentar un ambiente en el que se pueda crear con toda libertad obras en acero inoxidable. Hernández Urbán busca construir un puente entre su comunidad, la que comparte la comida, el hospedaje, sus fiestas, sus tradiciones, su saber hacer, y los escultores que comparten su ser y el producto de su experiencia, que permanece en la comunidad. En esta inmersión en otra cultura cada participante ofrece su propia individualidad, exponiendo las posibilidades que cada quién aprecia en el material, explorando formas de tratarlo, discutiendo conceptos formales de la escultura, experimentando nuevas técnicas y otros temas que surgen en el transcurso del trabajo de creación-realización.

Hernández Urbán explica a la prensa que los escultores - célebres o apenas iniciados en este arte - "han enriquecido su lenguaje plástico, han experimentado este material que facilita la gran variedad de texturas que el artista requiere para obtener una mayor expresividad en su obra". También hace notar que aunque no ha sido su finalidad, se ha creado "un movimiento de paz", pues durante el Simposio conviven diferentes religiones, culturas, idiomas, hábitos, etc.

Estos simposia proporcionan una experiencia que nutre a los escultores con sensaciones, formas, colores, olores y sabores de otras formas de ser y de hacer, de trabajar en común y de vivir las fiestas. A su vez, la población se enriquece con el contacto con nuevas formas de expresión, lenguas, signos, técnicas, gustos, en fin, con expresiones contemporáneas con diversos orígenes. Ambos grupos tienen la oportunidad de comprender, aprender y construir nuevas formas de sentir y de expresión?

17 Los artistas participantes en el simposio dejan una obra única. Los escultores restituyen a la comunidad de Tultepec el material proporcionado, pero trabajado de forma explícita. Es así como se cumple el trabajo de organización de una experiencia estética. Ted Carrasco, célebre escultor boliviano, subraya el diálogo entre la subjetividad y el entorno. Mostrando una pieza de su obra, afirma que la forma que él realizó es su manera de sentir la materia, que surge del diálogo íntimo con ella. Insiste en que las sensaciones adquiridas se procesan en cada persona y que la manera de decir y de expresarse es individual. Es por eso que el producto de una obra de arte es irrepetible.

\section{La obra producida}


Imagen 3. Obra realizada en el Simposio Internacional de Escultura en Acero Inoxidable, 2009

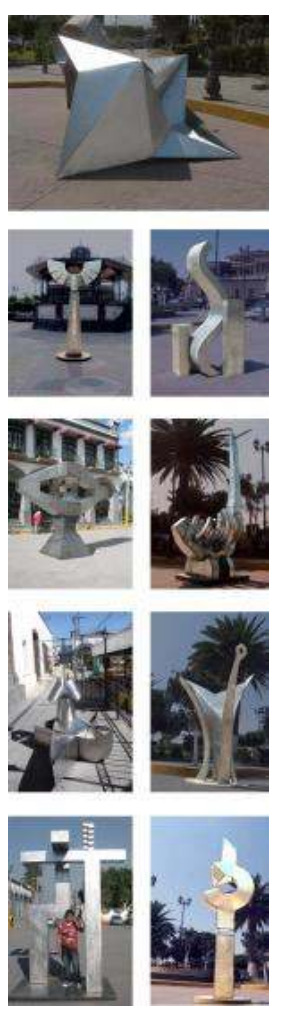

El "Simposio Internacional de Escultura en Acero Inoxidable" es el primero en su género realizado en el mundo. Desde 1992 los participantes, llegados de todo el mundo, trabajan en el taller de escultura que se encuentra junto a la Escuela de Bellas Artes de Tultepec. El Simposio abre la invitación y los escultores envían un proyecto de lo que les gustaría realizar. Entonces inicia el proceso de diálogo. A la llegada a Tultepec, los escultores son con frecuencia hospedados por habitantes de la población con quienes conviven durante todo el proceso. Se establece una amistad en la convivencia cotidiana, con un espíritu de apertura que lleva al entendimiento de culturas, no importando las diferencias. El contacto es humano y este hecho transforma y, como diría uno de los anfitriones, "ennoblece".

Los organizadores entregan a cada escultor un número igual de planchas de acero inoxidable de 2.50 metros por 1.20. También proporciona el equipo básico: cortador de plasma, soldadoras, máquinas roladoras, etc. Algunas veces los escultores utilizan otro material que puede ayudarles a realizar su obra. Los participantes se organizan en las diferentes actividades para realizar la escultura. También participan estudiantes de la Escuela de Bellas Artes que buscan formarse en la práctica. El espacio del taller siempre queda pequeño, por lo que se utiliza parte de la banqueta exterior de la Escuela para colocar partes de esculturas y de la obra terminada. A pesar de esta dificultad de espacio, el taller se mantiene abierto para recibir a los curiosos que desean ver los avances de cada escultor. Durante todo el simposio los participantes comparten ideas, problemas y soluciones técnicas, se coordinan para ayudarse entre todos a manipular las piezas, etc.

Durante la comida, los breves descansos y la noche, se discuten temas como la monumentalidad de una obra ${ }^{8}$, la simbología que cada quien utiliza, las alternativas conceptuales, así como las noticias de uno u otro país o región. En este ambiente de 
intenso trabajo intelectual, físico y emocional se han realizado más de 300 obras de escultores de treinta y siete países: Alemania, Argentina, Bélgica, Brasil, Bolivia, Bulgaria, Canadá, China, Corea, Costa Rica, Croacia, Cuba, Ecuador, Egipto, España, Estados Unidos, Francia, Grecia, Guatemala, Holanda, India, Inglaterra, Italia, Japón, Luxemburgo, México, Nepal, Perú, Portugal, Rumania, Rusia, Tailandia, Turquía, Ucrania, Uruguay y Venezuela.

21 Sin mencionar el apoyo financiero de la población de Tultepec y de empresas metalúrgicas y mecenas como Don Juan Autrique Gómez, el Simposio no cuenta con una fuente constante de financiamiento. Aunque los principales patrocinadores han sido instituciones gubernamentales - el Instituto Mexicano del Seguro Social, ayuntamientos, gobiernos de los Estados, institutos encargados de la cultura y las artes, etc. -, puede decirse que esta importante experiencia de práctica creativa se encuentra fuera del circuito del financiamiento de la obra pública en México9.

La búsqueda de recursos, que recae en el organizador principal, Miguel Hernández Urban, es siempre azarosa. Sin embargo, se mantiene la certeza de su realización anual, lo que ha permitido una respuesta importante tanto de los participantes, quienes han creado una red consistente, como de la población local que asegura su participación en la festividades y segura el incremento de su patrimonio artístico. Las obras elaboradas en Tultepec, ligeras y monumentales, permiten que se expongan constantemente en avenidas y recintos de las grandes ciudades mexicanas y de los Estados Unidos. Algunas han sido adquiridas por ayuntamientos, instituciones o empresas.

23 A nivel internacional, es notoria la influencia del Simposium en la aparición de otros eventos similares en diversos países, en los que se utiliza el mismo material. La discusión en Tultepec dió origen a la idea de crear la "Asociación Internacional de Eventos de Escultura Monumental", con sede en Italia, y cuyo objetivo es el de promover el arte público, crear una red internacional de colaboración y de soporte recíproco entre los miembros, así como acercar al público. 
Imagen 4. Paradise Flower. Obra de Ted Carrasco, acero inoxidable y vidrio 460 × $240 \times 240 \mathrm{~cm}$

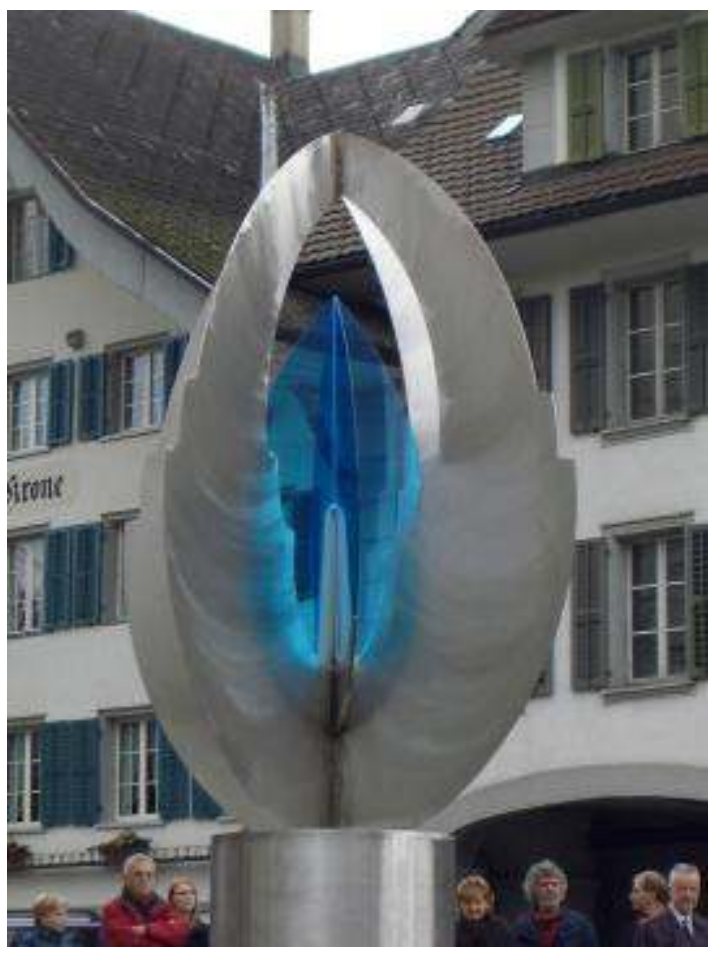

International Skulpturensymposium 2006, Suiza. Evento inspirado en el movimiento de Tultepec

Es importante continuar la observación de este importante movimiento de creación artística. La mancha urbana de la Ciudad de México toca ya a parte de este municipio y sin embargo, las estrategias de recreación y de renovación de las tradiciones, a través de la adaptación de materiales y formas de la vida cotidiana, pareciera que no sólo permite resistir a la homogenización cultural, sino que fortalece y renueva sus características identitarias particulares. Ciertamente, en otras zonas urbanas de México existen otros movimientos artísticos importantes que deberían ser estudiados. Para ello, es importante analizarlos desde el centro mismo de la actividad creativa e incluir a los actores participantes que, a nuestro juicio, no son debidamente apreciados al estudiar exclusivamente las obras realizadas.

\section{BIBLIOGRAFÍA}

BARLOW, Roberto y BYRON, MacAfee, 1982, Glifos del Códice Mendocino (Elementos fonéticos), Cuernavaca, Fonapas-Morelos, 46p. Reproducción facsímil de la edición original de 1949 Diccionario de elementos fonéticos en escritura jeroglífica (Códice Mendocino). México, UNAM- Instituto de Investigaciones Históricas UNAM.

DEWEY, John, L'art comme expérience. 2010, Paris, Gallimard. (1915 University Press Drive, Illinois) HERNÁNDEZ URBÁN, Miguel. Pagina web: http://miguelhernandezurban:com 
HENNION, A., 2007. La passion musicale : une sociologie de la médiation, Paris: Ed. Métailié.Instituto Nacional de Estadística y Geografía. Página web: https://www.inegi.org.mx/ Municipio de Tultepec. Página oficial del gobierno: http://www.tultepec.gob.mx Nathalie Heinich « La construction d'un regard collectif: le cas de l'Inventaire du patrimoine », Gradhiva 1/2010 (n 11), p. $162-180$

HENNION, A., 2007. La passion musicale : une sociologie de la médiation, Paris: Ed. Métailié.

SAUVAGEOT, A., 1994. Voirs et savoirs : Esquisse d'une sociologie du regard, Presses Universitaires de France - PUF.

SENNETT, R., 2010. Ce que sait la main : La culture de l'artisanat, Albin Michel.

VÁZQUEZ Urbán Antonio, Federico García García, Liborio Gutiérrez. Enciclopedia de los Municipios y Delegaciones de México. Estado de México. H. Ayuntamiento de Tultepec- Instituto para el Federalismo y el Desarrollo Municipal-Secretaría de Gobernación: http://e-local.gob.mx.

VILLAFUERTE Susana. Notas - Charlas con Miguel Hernández Urbán durante los Simposios 2002, 2003,2006

VILLAFUERTE Susana. Notas de charlas con escultores (1999-2011).

\section{NOTAS}

1. Tultepec proviene del náhuatl, y se compone de Tul de Tol, Tollin, "tule"; de Tepetl, "cerro" y c de co, "en". El tule es una planta acuática, característica del islote de Xaltocán, antiguo sitio del pueblo original.

2. Estos datos son variables debido a los conflictos territoriales con los municipios colindantes. En 2005, el censo del Instituto Nacional de Estadística y Geografía (INEGI) reportó 110,145 habitantes. En el censo de 2010 se contaron 91,808 pobladores. Todas las estadísticas mencionadas provienen de la misma fuente.

3. Músicos destacados del siglo pasado (intérpretes y compositores): Mardonio Urbán Solano (1868-1955), músico, escritor, poeta, dramaturgo y cronista. Hernesto Urbán Rodíguez (1894), Ricardo Vázquez Pineda (1894), Victor Manuel Urbán Silva (1894), Andrés Urbán (1870), Prudenciano García (1880), Antonio Jesús Vázquez Pineda (1894), Heleodoro Urbán Solano (1884), Ángel Vázquez Pineda, Agustín Urbán Silva. Músicos contemporáneos: Victor Urbán Velasco, Gerardo Urbán Velásco, Francisco Vázquez García, Francisco Romero Linares, J. Isabel Vázquez Solano, Isaías Vázquez Solano, Francisco Sánchez Rodríguez, Felipe Urbán Solano, Carmelo Sánchez Fiesco, Ricardo Sánchez Fiesco, Dionisio Sánchez Luna, Arsenio Urbán Vázquez, José Ángel Urbán Velasco, Celso Solano Solano, Miguel Hernández Víquez. Pintores y escultores: Miguel Hernández Urbán, Joaquín González Romero, Margarito González Solano, Gregorio González Solano, Albino Luna Sánchez.

http://tultepec.gob.mx/

4. Pirotécnicos destacados por sus experimentos y creaciones: entre 1880 y 1990, Agustín, Miguel y Gregorio Fiesco. Entre 1900 y 1920, José Solano Urbán, quien revolucionó la juguetería, los castillos y los fuegos pirotécnicos. Alrededor de 1920, Felipe Reyes obtuvo la luz fina roja y amarilla. Por las mismas fechas con Ángel Guadalupe Flores fueron inventores de la luz de estrella y de la luz de bengala, del cohete bomba, del cohete morado y de la bomba de tres tiempos. Cirilo Sánchez inventó por las mismas fechas los globos aerostáticos de siete metros de altura que jamás se volvieron a ver después de su muerte. En los treintas, Tomás Romero inventó los fuegos de movimiento. En 1933 Felipe Fiesco y Ángel Urbán Rivero inventan el blanco eléctrico; Marcos Romero y Felipe Fiesco inventan la bomba araña. En 1934, Julián Romero 
inventa la rueda con dos figuras y Marco Romero perfecciona la rueda con dos figuras. http:// tultepec.gob.mx/

5. Acero inoxidable, aleación de hierro, carbono (como todos los aceros, para adquirir propiedades de elasticidad, dureza y resistencia), con cromo, a veces níquel y otros elementos, para obtener una resistencia a la corrosión. Experimentado desde el siglo XIX, su uso actual inicia a principios del siglo XX.

6. El primer Simposio de Escultura tiene lugar en 1959, Fue organizado por Karl Pranti en Saint Margarethen, Austria. Pranti ocupaba un encargo público y se sentía aislado en aquella población. Por ello, reunió a varios amigos escultores para aprovechar la cantera de piedra caliza de ese poblado y trabajar juntos. Después de esa experiencia se organizaron en todo el mundo simposia de escultura en metal, piedra, madera, concreto, quedando las obras como patrimonio de las ciudades. Leónard Rachita narra en el primer número del boletín de la Asociación Internacional para los Simposios de Escultura con sede en Paris, que en 1989 había reseñado 400 simposia de escultura: "Los simposios han creado interferencias culturales en una superposición de estilos y de orientaciones artísticas de una gran variedad y ejercen una influencia innegable sobre la escultura contemporánea." (Rachita, 2006, p. 38).

7. Para nosotros la educación de los sentidos y la formación de gustos estéticos, se construye en la experiencia vivida. (Sauvageot 1994; Hennion 2007).

8. La monumentalidad es una característica óptica de las formas, no el tamaño de la obra, me explicaban los escultores.

9. En la Ciudad de México, la escultura monumental se ha desarrollado en gran medida por el circuito del encargo para obra pública por parte de particulares, empresas e instituciones. Es el caso de la obra pública creada por Gunther Gerzso, Mathias Goeritz, Leonora Carrington, Bian Nissen, Manuel Felguérez, José Luis Cuevas, Juan Soriano, Jesús Mayagoitia, Vicente Rojo, Marina Lascaris, Jorge Yáspik, Ricardo Regazzoni, Ivonne Domenge, Paloma Torres, entre otros. En Guadalajara, San Luis Potosí y otras ciudades de provincia se han realizado algunos simposia que han dotado de obras a estas urbes.

\section{RESÚMENES}

El movimiento de escultura monumental en acero inoxidable que se desarrolla en Tultepec, Estado de México, permite reflexionar acerca de la creación artística contemporánea y sobre su relación con las estrategias de recreación y renovación de tradiciones de una localidad del norte de la zona metropolitana. En este trabajo se presenta un estudio sobre el modo en el que se mantiene la participación comunal en las festividades tradicionales y cómo se adoptan y adaptan elementos modernos a sus prácticas creativas, lo que al mismo tiempo permite reforzar la identidad y hacerse presente en el mundo del arte internacional.

Le mouvement de sculpture monumentale en acier inoxydable qui se développe à Tultepec, Mexique, nous permet de mener une réflexion sur la création artistique contemporaine et son rapport avec les stratégies de re-création et de renouvellement des traditions d'une localité du nord de la zone métropolitaine. Nous présentons dans ce texte la façon dont sont conservés certains modes de participation collective dans les festivités traditionnelles et comment des éléments modernes s'adaptent à ces pratiques créatives et les adoptent, ce qui permet de renforcer leur identité, et d'acquérir une présence dans le monde de l'art international. 
ÍNDICE

Palabras claves: escultura monumental, acero inoxidable, creatividad, tradición - modernidad, Tultepec, México

\section{AUTOR}

\section{SUSANA VILLAFUERTE}

Sociologue, Centre d'études des rationalités et des savoirs, LISST-CERS (UMR CNRS 5193), Université de Toulouse 2-Le Mirail 